\title{
Uma invenção
} de Laplace e Lavoisier

\author{
a propósito da utilização \\ de calorímetros nos laboratórios \\ do ensino secundário
}

Em 18 de Junho de 1783, Laplace e Lavoisier fizeram à Academia de Ciências de Paris uma comunicação (publicada no tomo $\mathrm{X}$ das Obras Completas de Laplace) em que apresentaram um método e um instrumento de sua invenção que, em sua opinião, permitia em melhores condiçס̃es que outros anteriormente conhecidos medir diversas grandezas térmicas. Conjuntamente com a descrição do método apresentaram uma lista de grandezas que ambos tinham medido durante o Inverno anterior. A extensão desta lista: calores específicos de sólidos e líquidos, calor libertado em diversas reacçōes químicas, e até calor libertado pelo corpo de animais colocados dentro do aparelho, faz pensar que se tratou efectivamente de um dos primeiros trabalhos sistemáticos de determinação de grandezas térmicas. Comunicada à Academia das Ciências de Paris era, certamente, a expressão avançada dos conhecimentos científicos da época. É de crer que tenha estado na origem de tabelas que depois vieram a ser publicadas em livros.

O calorímetro de Laplace e de Lavoisier, pois de um calorímetro se tratava, hoje, quase esquecido, não parece, assim, ter sido uma simples curiosidade, mas sim um instrumento que teve um papel significativo no desenvolvimento das Ciências.

$\mathrm{O}$ aparelho de Laivosier e de Laplace só podia ser usado no Inverno, ou nos "países nórdicos" pela simples razão da sua utilização exigir gelo que na época não se sabia fabricar. Em contrapartida permitia com uma razoável precisão medir calores específicos sem o uso de qualquer termómetro. Tratando-se dum aparelho que pode ser feito por um simples latoeiro, a sua utilização nos laboratórios do ensino secundário, hoje em dia em que por toda a parte há frigoríficos que produzem gelo, parece altamente aconselhável.

$\mathrm{O}$ próprio engenho do método usado pelos dois grandes nomes da Ciência, em si, é uma lição.

$\mathrm{Na}$ sua comunicação, numa primeira fundamentação teórica, Laplace e Lavoisier começam por considerar uma esfera de gelo oca numa atmosfera exterior à pressão de uma atmosfera e com uma temperatura de preferência baixa mas superior a zero. O calor recebido do exterior vai progressivamente fundindo o gelo do exterior, mas sem alterar a temperatura da esfera e do cavado interior, que se mantem a zero graus. Introduzindo no interior da esfera um corpo a uma temperatura elevada (que pode ser 100 graus) a sua temperatura desce até zero, perdendo o corpo simultaneamente calor, que vai fundir o gelo da superfície da cavidade interior. Medindo a água líquida proveniente desta fusão (que se mantém a zero graus) e conhecido o seu calor latente de fusão, é possível conhecer o calor perdido pelo corpo e, consequentemente, a sua capacidade calorífica e calor específico (calor específico médio entre zero e 100 graus).

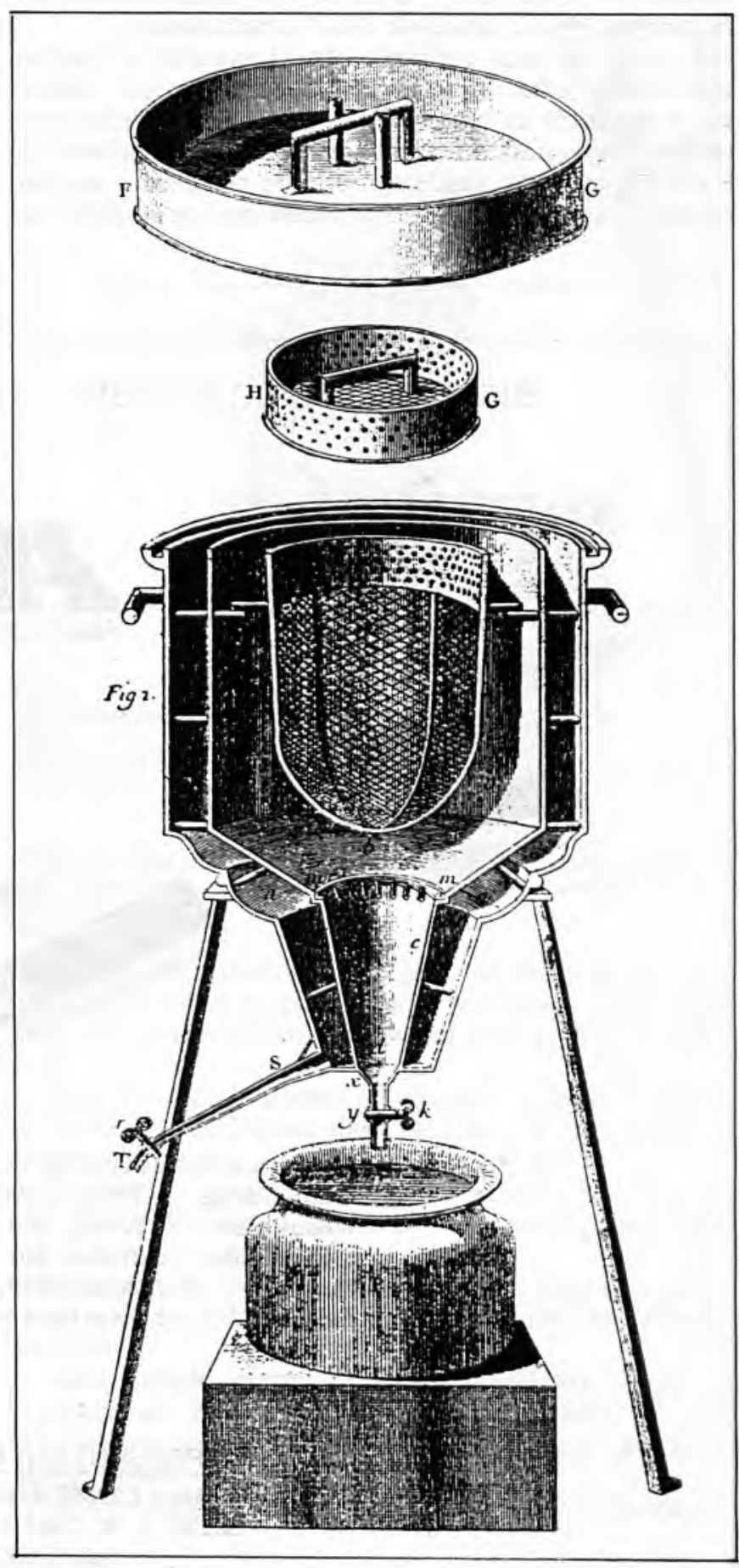

Figura: Montagem a partir da estampa original publicada nas $M e ́$ moires de l'Académie des Sciences (1780)

\footnotetext{
a Departamento de Física, IST.
} 
O calorímetro (descrito na figura anexa, copiada da estampa original entregue à Academia) é um dispositivo destinado a permitir a realização prática, tão aproximada quanto possível, da experiência teórica. O envólucro exterior (a) e a tampa superior (FG) são cheios com gelo que se funde lentamente e que assegura a temperatura zero no interior. A água líquida proveniente desta fusão sai pela torneira $(t)$. A zona intermédia (b) e a tampa interior (HG) tem gelo que só funde quando no espaço interior é metido um corpo a uma temperatura mais alta. A água líquida proveniente desta fusão sai pela torneira (k) depois de passar por um ralo e uma peneira colocados na secção $(\mathrm{m})$ que não deixam passar partículas sólidas. A zona interior é limitada por uma rede e a ela se tem acesso levantando as tampas o que pode ser feito rapidamente.

No texto da sua comunicação, Lavoisier e Laplace transmitem uma série de informaçð̄es práticas tendentes a melhorar as condiçð̌es de experiência, resultantes de um saber prático acumulado durante um Inverno de trabalho, que vão desde o modo de preparar e acondicionar o gelo e rapidez e duração das operaçōes, até aos cuidados a ter com os porquinhos da İndia que colocaram dentro da máquina por períodos de cinco a dez horas (e que segundo os autores nada terão sofrido). Dispensamo-nos de reproduzir aqui essas indicaçð̄es que poderão no entanto ser úteis a professores do secundário que a dois séculos de distância queiram pôr os seus alunos a realizar as mesmas experiências.

Seria útil e educativo que alguns deles o fizessem. Poder ser ensinado quase directamente por Laplace e Lavoisier é um previlégio a não desperdiçar.

Enganam-se os que julgam que a modernidade passa pelo abandono das coisas antigas, sobretudo quando elas continuam a ser úteis, práticas, simples, económicas e inteligentes.

De qualquer modo, a situação com que nos defrontamos hoje, de ninguém levantar o braço quando um professor de uma escola superior pergunta aos seus alunos quais de entre eles fizeram experiências de calorimetria no secundário, não é uma situação de progresso, mas de profundo retrocesso. Tentemos, com um mínimo de bom senso, pôr termo a ela.

\section{simples, eficientes $\quad \frac{*}{*} \quad$ práticas, robustas}
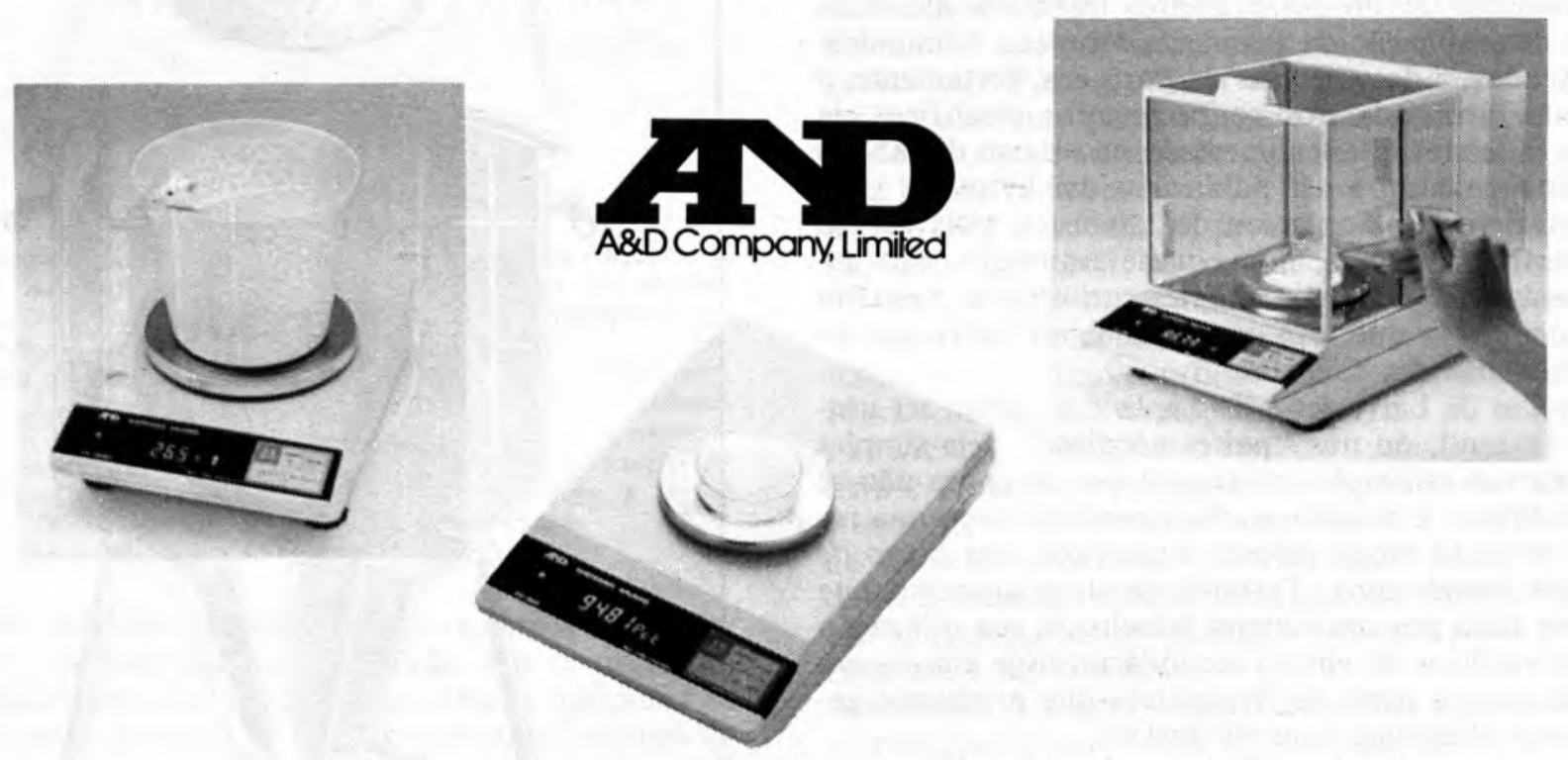

A "A E D" apresenta a nova série de balanças de precisão série FX / FY Capacidade : $310 \mathrm{~g}, 3100 \mathrm{~g}, 6100 \mathrm{~g}$

Resolução : $0.01 \mathrm{~g}, 0.01 \mathrm{~g}, 0.1 \mathrm{~g}$

Calibração : digital e muito fácil

Funções : PESAGEM, CONTAGEM, RESULTADOS PERCENTUAIS

Opção : Interface RS-232C

REPRESENTANTES EXCLUSIVOS EM PORTUGAL:

VIARA COMERCIAL [MAQUINAS], LDA

SEDE : R. Delfim Ferreira, $509-4100$ Porto

telef. $683763 / 671351 / 671352$

FILIAL: Avenida do Brasil, 145-C - 1700 Lisboa

telef. $804551 / 804552$ 